\title{
Provinces press for e-cigarette crackdown
}

$\mathrm{P}$ rovincial and territorial health ministers urged stronger federal action on flavoured tobacco products and e-cigarettes, following a Sept. 30 meeting in Banff, Alberta. Progress on dementia and a panCanadian pharmaceutical alliance also topped the agenda.

Tobacco companies have taken advantage of regulatory loopholes to market flavoured products to young people, British Columbia Health Minister Terry Lake told reporters.

Health Canada's proposal to extend the ban on flavoured cigarillos to other cigar types doesn't go far enough to close these gaps, said Lake. The proposed changes would still allow menthol and certain "adult flavours," such as port, wine, rum and whisky. And the ban wouldn't apply to other popular tobacco products, including flavoured products for water pipes (hookahs) and chewing tobaccos.

The ministers also want stronger controls on e-cigarettes. Increasing popularity of the devices is paralleled by concern that they encourage, rather than supplant, tobacco use. On Sept. 29, Federal Health Minister Rona Ambrose deferred the issue to the Standing Committee on Health "due to a lack of evidence on the benefits or harms."

"We encourage the federal government to put a framework in place to protect particularly young people from electronic cigarettes and make sure they're regulated in the way that tobacco is regulated," said Lake.

The World Health Organization has urged the same, advising bans on indoor use of e-cigarettes and sales of the devices to minors until more is known about the risks. South of the border, a majority of states and hundreds of municipalities already have such strictures. And a handful of Canadian municipalities prohibit e-cigarette use at work and in public spaces.

\section{Dementia}

Prince Edward Island Minister of Health and Wellness Doug Currie said the provinces and territories are keen to start a similar collaboration on dementia under a new task force on aging. "Our focus will be ... looking at best practices and research, at the challenges all the provinces are facing as we continue to provide appropriate care and services for our aging population."

But the ministers stop ped short of promising the national dementia care strategy that some hoped would come from the meeting. Currently, Canada's only national dementia plan focuses almost exclusively on research.

Research and innovation

"It's encouraging that the provincial-territorial health ministers recognize the need for action," says Robert Cunningham, a lawyer and senior policy analyst for the Canadian Cancer Society. And provinces need not wait for federal legislation to implement their own bans. "There are lots of examples of how this can be done and this is clearly within provincial responsibility."

\section{Pharmaceutical alliance}

The ministers reported "tremendous success" in other provincial-territorial initiatives, including a pan-Canadian pharmaceutical alliance.

Since 2010, the drug purchasing initiative has accrued a quarter of a billion dollars in annual savings for the provinces, said Ontario Minister of Health and Long-Term Care Dr. Eric Hoskins. "But it's important that federal leadership be there at the table ... including financially," particularly to bring down the cost of rare or orphan drugs.

"This is not an effort that can be done on a patchwork or individual basis," said Hoskins. are important, but are not a "substitute for immediate help to families who must navigate whatever support services might be available," says Susan Eng, vice president for advocacy at CARP. The nonprofit seniors lobby group is calling for a "paradigm shift" in dementia care, including better training for health workers and caregivers, and more specialized home care and long-term care.

"As with most aspects of the health care system, quality and access depend on postal code, so it was a missed opportunity ... not to even set up a plan to discuss a national strategy," says Eng.

According to the Canadian Medical Association, Canada spends $\$ 2.3$ billion a year "warehousing seniors" in hospital beds because long-term or home care services are not available. A third of these patients have dementia.

The provincial-territorial ministers met Oct. 1 with Ambrose. - Lauren Vogel, CMAJ

CMAJ 2014. DOI:10.1503/cmaj.109-4914 